\title{
PAPERS
}

\section{Post-immunisation gastritis and Helicobacter infection in the mouse: a long term study}

\author{
P Sutton, S J Danon, M Walker, L J Thompson, J Wilson, T Kosaka, A Lee
}

\begin{abstract}
Background and aims-Helicobacter pylori is a major cause of peptic ulcers and gastric cancer. Vaccine development is progressing but there is concern that immunisation may exacerbate Helicobacter induced gastritis: prophylactic immunisation followed by challenge with $H$ felis or $\mathrm{H}$ pylori can induce a more severe gastritis in mice than seen with infection alone. The aim of this study was to investigate the relationship between immunity to Helicobacter infection and postimmunisation gastritis.
\end{abstract}

Methods-(1) C57BL/6 mice were prophylactically immunised before challenge with either $\boldsymbol{H}$ felis or $\boldsymbol{H}$ pylori. Histopathology and colonisation were assessed one month post-challenge. (2) C57BL/6 mice were prophylactically immunised against $H$ felis infection and gastritis assessed up to 18 months post-challenge.

Results-Prophylactic immunisation induced a reduction in bacterial colonisation following $\boldsymbol{H}$ felis challenge which was associated with increased severity of active gastritis with neutrophil infiltration and atrophy. However, immunised mice challenged with $H$ pylori SS1 had little evidence of pathology. Long term follow up showed that post-immunisation gastritis was evident at three months. However, from six months onwards, although immunised/challenged mice still developed gastritis, there was no significant difference between inflammation in these mice and infected controls. Postimmunisation gastritis was not associated with the serum antibody response. Immunisation prevented the formation of secondary lymphoid aggregates in the gastric tissue.

Conclusion-The $\boldsymbol{H}$ felis mouse model of post-immunisation gastritis is the most extreme example of this type of pathology. We have shown in this model that postimmunisation gastritis is a transient event which does not produce long term exacerbation of pathology.

(Gut 2001;49:467-473)

Keywords: Helicobacter; immunisation; post-immunisation gastritis
Helicobacter pylori is a Gram negative bacterium which infects solely the gastric mucosa. It has a known association with peptic ulcers, gastric cancer, and mucosal associated lymphoid tissue (MALT) lymphoma. ${ }^{1-3}$ The current eradication regimen for infection is antimicrobial therapy and concurrent acid suppression. Unfortunately, the development of antibiotic resistant strains of $H$ pylori is already raising concerns about the long term use of these combination treatments. ${ }^{4}$ For this reason, much attention has focused on the production of an effective vaccine. Using mouse models of infection with $H$ pylori or the closely related $H$ felis, it has been shown that immunisation with whole cell sonicate or single antigens protects mice against later bacterial challenge ${ }^{5-10}$ or even when given therapeutically ${ }^{11}{ }^{12}$ if administered with a mucosal adjuvant.

A consistent observation has been that prophylactic immunisation is often accompanied by an increase in the severity of gastritis in the challenged animals. This phenomenon has been termed post-immunisation gastritis and is an important issue which needs to be addressed if a human vaccine is to become a reality. It has mainly been seen following challenge with $H$ felis $^{13}$ but has also been reported with $H$ pylori. ${ }^{14}$

Post-immunisation gastritis has only been studied in short term experiments and its long term effects are unknown. Similarly, no published studies have followed immunised and challenged mice to assess the life long effect of vaccination on bacterial colonisation. This study reports on two immunisation studies in C57BL/6 mice. The first is a short term study which compares post-immunisation gastritis induced by challenge of immunised mice with $H$ felis and the Sydney strain of $H$ pylori. The second study examines the course of gastritis in immunised mice for up to 18 months after bacterial challenge with $H$ felis.

Materials and methods

ANIMALS

C57BL/6 age matched female mice were obtained from the Animal Resources Centre, Perth, Australia. All protocols involving animal

Abbreviations used in this paper: $\mathrm{BHI}$, brain heart infusion; PBS, phosphate buffered saline; CT, cholera toxin; GAIS, gland active inflammatory score; BSA, bovine serum albumin; MALT, mucosal associated lymphoid tissue. 
Table 1 Time frames used for the studies

\begin{tabular}{lllllll}
\hline & & \multicolumn{1}{l}{$\begin{array}{c}\text { Immunisation } \\
\text { (week) }\end{array}$} & & $\begin{array}{l}\text { Bacterial } \\
\text { challenge } \\
\text { (week) }\end{array}$ & $\begin{array}{l}\text { Collection } \\
\text { (time (months) } \\
\text { post-challenge) }\end{array}$ \\
\hline Study 1 & 1 & 2 & 3 & 4 & 8 & 1 \\
Study 2 & 1 & 2 & 3 & 4 & 8 & $3,6,12,18$ \\
\hline
\end{tabular}

experimentation were approved by the Animal Care and Ethics Committee at the University of New South Wales (ACE 96/113).

EXPERIMENTAL PROCEDURE

The time frames used for these studies are shown in table 1.

\section{HELICOBACTER: ANTIGEN PREPARATION AND} BACTERIAL CHALLENGE

$H$ felis CS1 (ATCC 49179) ${ }^{15}$ was grown on Campylobacter selective agar consisting of 5\% (v/v) sterile horse blood in blood agar base No 2 (Oxoid Ltd, Basingstoke, UK) and Skirrow's supplement $(10 \mu \mathrm{g} / \mathrm{ml}$ vancomycin (Sigma Chemical Co., St Louis, Missouri, USA), $5 \mu \mathrm{g} / \mathrm{ml}$ trimethoprim lactate (Sigma), $2500 \mathrm{IU} / 1$ polymyxin B (Sigma), and $5 \mu \mathrm{g} / \mathrm{ml}$ amphotericin B (ER Squibb \& Sons, Princetown, New Jersey, USA)). Plates were incubated in an anaerobic jar with a microaerophilic gas generating kit (code No BR 56; Oxoid) for two days at $37^{\circ} \mathrm{C}$. H pylori strain $\mathrm{SS} 1^{16}$ was grown for two days at $37^{\circ} \mathrm{C}$ with $10 \% \mathrm{CO}_{2}$ and $95 \%$ humidity in brain heart infusion (BHI) broth culture (Oxoid) with 5\% $(\mathrm{v} / \mathrm{v})$ horse serum and Skirrow's supplement.

For antigen preparation, cells were harvested in phosphate buffered saline (PBS) and sonicated with a Branson Sonifier fitted with a microtip (Branson Ultrasonics Corporation, Danbury, Connecticut, USA). The protein content of the sonicate was determined using the Bio-Rad DC protein assay (Bio-Rad, Regents Park, Australia) and then stored at $-70^{\circ} \mathrm{C}$ until use.

For challenge, Helicobacter were harvested in BHI broth (Oxoid) and the final concentration was adjusted to approximately $10^{8}$ bacteria $/ \mathrm{ml}$. Mice were inoculated intragastrically with a single dose of $0.1 \mathrm{ml}$ of bacterial suspension ( $10^{7}$ bacteria).

IMMUNISATION

Mice were immunised with four weekly orogastric doses of $1 \mathrm{mg}$ of either $\mathrm{H}$ felis or $H$ pylori whole cell sonicate plus $10 \mu \mathrm{g}$ of cholera toxin (CT) as adjuvant (Sigma) in PBS. Age and sex matched control animals were dosed with PBS alone.
SAMPLING

At termination of the experiments, mice were anaesthetised by intraperitoneal injection of $50 \mathrm{mg} / \mathrm{kg}$ of ketamine and xylazine (Parnell Laboratories, NSW, Australia). Blood was collected from the aortic arch and sera stored at $-20^{\circ} \mathrm{C}$. Mice were sacrificed by cervical dislocation and the stomachs removed. Half of each stomach was fixed in $10 \%$ formal buffered saline and processed for histopathology. For $H$ pylori infected mice, half of the stomachs were collected into a preweighed bijou containing $2 \mathrm{ml}$ of BHI broth for quantitative culture.

ASSESSMENT OF COLONISATION AND GASTRIC PATHOLOGY

$H$ felis does not form colonies in culture and therefore colonisation was assessed histologically. Sections of stomach $(4 \mu \mathrm{m})$ were cut and stained by the modified Steiner silver method. The degree of colonisation in $H$ felis infected mice was assessed by semiquantitative analysis of bacteria. The most dense region of bacterial colonisation was noted and graded from 0 to 4 where $0=$ no bacteria, $1=1-2$ bacteria/crypt, $2=3-10$ bacteria/crypt, $3=11-20$ bacteria/ crypt, and $4=>20$ bacteria/crypt.

For assessment of colonisation by $H$ pylori, half stomachs were weighed and homogenised with an Ultra Turrax homogeniser (John Morris Scientific Ltd). One in 10 serial dilutions were prepared in BHI broth and $200 \mu \mathrm{l}$ aliquots spread over GSSA selective agar plates-a blood agar base with $5 \%$ horse blood supplemented with vancomycin $(10 \mathrm{mg} / \mathrm{ml})$, polymyxin $B(0.33 \mathrm{mg} / \mathrm{ml})$, bacitracin $(20 \mathrm{mg} / \mathrm{ml})$, nalidixic acid $(1.07 \mathrm{mg} / \mathrm{ml})$, and amphotericin B $(5 \mathrm{mg} / \mathrm{ml})$. After five days of incubation under humidified microaerophilic conditions, colonies were counted. Colony forming units per gram of stomach tissue were calculated by multiplying the number of colonies counted by the dilution factor and dividing by the weight of the stomach tissue.

For assessment of gastric histopathology, blinded sections stained with haematoxylin and eosin were examined by light microscopy. Antral and body mucosa were graded separately; active inflammation was assessed by the presence of neutrophils and chronic inflammation by the presence of lymphocytes. The scoring system was graded as: $1=$ mild multifocal; $2=$ mild widespread or moderate multifocal; $3=$ mild widespread and moderate multifocal or severe multifocal; $4=$ moderate widespread;

Table 2 Corpal gastritis in immunised and challenged C57BL/6 mice. Post-immunisation gastritis in short term immunised/challenged mice. Bacterial colonisation and gastric pathology were assessed in control, infected, or immunised/challenged mice one month after challenge with Helicobacter felis or H pylori

\begin{tabular}{|c|c|c|c|c|c|c|c|c|c|}
\hline \multirow[b]{2}{*}{ Group } & \multicolumn{2}{|l|}{ Antrum } & \multicolumn{2}{|l|}{ Body } & \multirow{2}{*}{$\begin{array}{l}\text { Lymphoid } \\
\text { aggregates/ } \\
\text { follicles }\end{array}$} & \multirow[b]{2}{*}{ GAIS } & \multirow[b]{2}{*}{ Atrophy } & \multirow{2}{*}{$\begin{array}{l}\text { Submucosal } \\
\text { inflammation }\end{array}$} & \multirow[b]{2}{*}{ Colonisation } \\
\hline & Neutrophils & $C I$ & Neutrophils & $C I$ & & & & & \\
\hline H felis & & & & & & & & & Histology \\
\hline Control infected & $2(1-3)$ & $2(1-3)$ & $3(0-5)$ & $2(1-4)$ & $0(0-1)$ & $0(1-10)$ & $1(0-3)$ & $1.5(0-4)$ & $3.5(2-4)$ \\
\hline Immunised/challenged & $3(2-4)^{\star}$ & $2(0-3)$ & $4.5(4-5)^{\star}$ & $2(1-3)$ & $0(0)$ & $2.5(0-11)$ & $2(0-3)^{\star}$ & $1.5(0-3)$ & $0(0-3) \dagger$ \\
\hline H pylori & & & & & & & & & CFUs \\
\hline Control infected & $1(0-2)$ & $0(0-1)$ & $0(0-2)$ & $1(0-1)$ & $0(0)$ & $0(0)$ & $0(0)$ & $0(0)$ & $10.1(6.6)$ \\
\hline Immunised/challenged & $1(0-3)$ & $1(0-2)^{\star}$ & $1.5(0-2)^{\star}$ & $1(0-2)$ & $0(0)$ & $0(0)$ & $0(0)$ & $0(0)$ & $1.1(1.3) \ddagger$ \\
\hline
\end{tabular}

CI, chronic inflammation; GAIS, gland active inflammatory score; CFUs, colony forming units, $\times 10^{-6} / \mathrm{g}$ stomach tissue.

Scores given are median (range), except colony counts for $H$ pylori which are mean (SD).

$\star$ Significantly greater than the corresponding value in the infected control group $(\mathrm{p}<0.05$; Mann-Whitney); tsignificantly lower than the corresponding value in the infected control group $(\mathrm{p}<0.05$; Mann-Whitney); $\ddagger$ significantly lower than the corresponding value in the infected control group ( $<<0.01$; one way ANOVA). 
$5=$ moderate widespread and severe multifocal; and $6=$ severe widespread. The total number of lymphoid aggregates and follicles in each section were counted. The total number of glands with neutrophil infiltration in the crypt and lumen were also counted to produce a gland active inflammatory score (GAIS). Atrophy was evaluated on the degree of loss of parietal cells and mucus cell hyperplasia and assessed as zero, mild, moderate, or severe. For the purpose of statistical analysis, these were converted to 0,1 (mild), 2 (moderate), or 3 (severe). Submucosal inflammation (that is, inflammation below the muscularis mucosae) was assessed on a scale of $0-6$ as above.

MEASUREMENT OF ANTI-HELICOBACTER SERUM ANTIBODIES

Serum anti-Helicobacter antibody levels were measured by standard enzyme linked immunosorbent assays. In brief, duplicate wells of Maxisorp microtitre plates (Nunc, Denmark) were coated with $50 \mu \mathrm{l}$ of $H$ felis or $H$ pylori lysate $(100 \mu \mathrm{g} / \mathrm{ml})$ in carbonate buffer, pH 9.6. After washing with PBS- $0.5 \%$ (v/v) Tween 20, the wells were blocked for two hours with PBS containing $1 \%(\mathrm{w} / \mathrm{v})$ bovine serum albumin (PBS-BSA) and then incubated overnight at $4^{\circ} \mathrm{C}$ with $100 \mu \mathrm{l}$ aliquots of sera, diluted 1 in 20 in PBS-BSA. Bound antibody was detected by incubation at room temperature with ratantimouse IgG, or IgA conjugated with alkaline phosphatase (Pharmingen, San Diego, California, USA), used at a dilution of $1 / 2000$ and $1 / 250$, respectively. Enzyme activity was determined by incubation with Sigma 104 phosphatase substrate tablets dissolved in diethanolamine buffer and absorbance measured at a wavelength of $405 \mathrm{~nm}$.

STATISTICS

Comparisons of $\mathrm{H}$ felis colonisation, gastric pathology scores, and serum antibody levels between infected and immunised mice were assessed by non-parametric Mann-Whitney analysis. Colonisation by $H$ pylori colony forming assay was assessed by the parametric ANOVA one way means test. Changes in $\mathrm{H}$ felis colonisation, gastric pathology scores, and serum antibody levels over time were assessed by non-parametric Kruskal-Wallis analysis.

\section{Results}

POST-IMMUNISATION GASTRITIS IN IMMUNISED MICE CHALLENGED WITH EITHER $H$ FELIS OR $H$ PYLORI

Groups of 10 C57BL/6 mice were either prophylactically immunised with $H$ felis lysate and CT before challenge with $H$ felis or with $H$ pylori lysate and CT before challenge with $H$ pylori. Control mice were dosed with PBS before infecting with the respective Helicobacter. Colonisation by $H$ pylori was assessed at one month post-challenge by colony count assay. $H$ felis does not readily form colonies and so colonisation was assessed histologically. In both cases, immunisation significantly decreased bacterial colonisation in all immunised mice compared with infected controls (table 2).

\section{A}
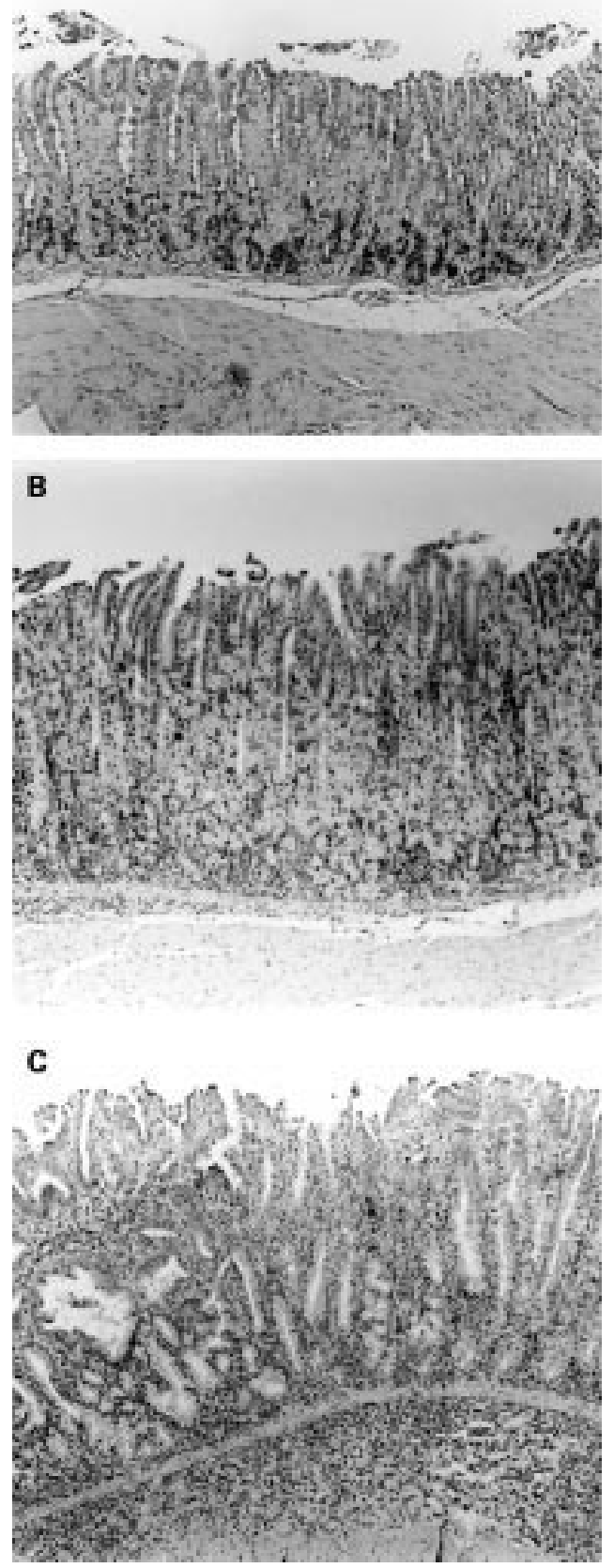

Figure 1 Histopathology. Photomicrographs (magnification $\times 148$ ) are representative of: $(A)$ normal mouse stomach; (B) Helicobacter felis infected stomach with moderate multifocal infiltration of lymphocytes; and (C) post-immunisation gastritis in a mouse prophylactically immunised and then challenged with $H$ felis. The section shown portrays infiltration of lymphocytes, with severe functional atrophy and severe submucosal inflammation.

Gastritis was independently assessed by two histopathologists (SD and MW). Mice infected with $H$ felis showed mild active and chronic gastritis, mild inflammation of the submucosa, and mild functional atrophy (table 2). However, immunised mice challenged with $H$ felis demonstrated post-immunisation gastritis, evidenced by a significant increase in active gastritis in both the antrum and body and the development of atrophy. Representative photomicrographs of the observed pathologies 


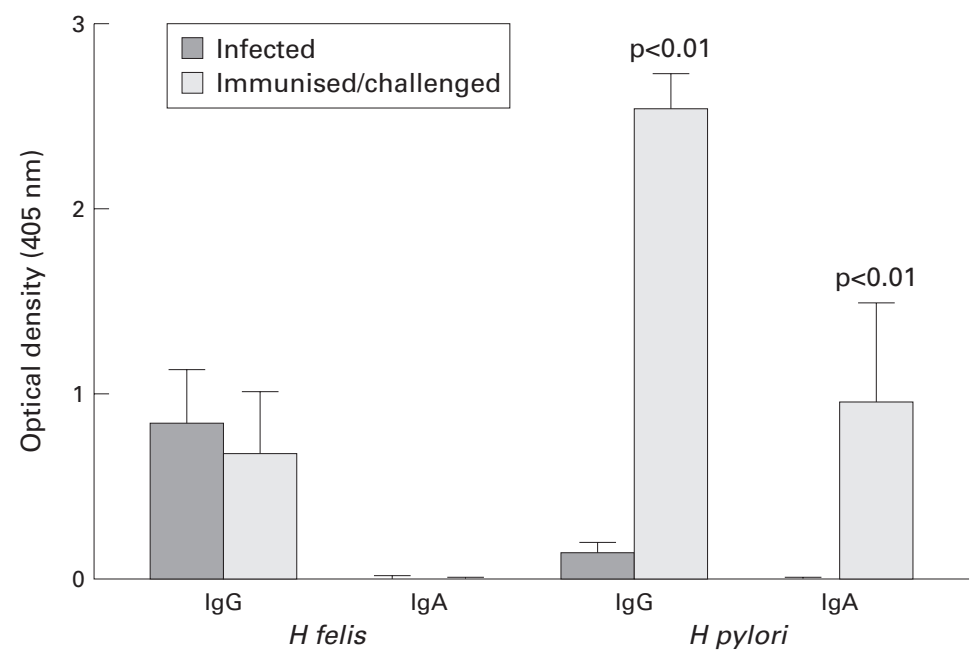

Figure 2 Serum levels of anti-Helicobacter antibodies following immunisation and challenge of mice with Helicobacter. Serum levels of anti-H felis and anti-H pylori IgG and IgA antibodies were assessed by ELISA; the y axis shows optical densities measured at 405 nm. $p$ values show significant differences (Mann-Whitney analysis).

induced by $H$ felis infection or postimmunisation gastritis following $H$ felis challenge are shown in fig $1 \mathrm{~B}$ and $1 \mathrm{C}$, respectively.

In contrast with mice infected with $H$ felis, those infected with $H$ pylori developed mild chronic gastritis with no evidence of atrophy, lymphoid follicle/aggregates, active inflammation, or submucosal inflammation. This was also true for the immunised mice challenged with $H$ pylori. There was a small but significant increase in chronic gastritis in the antrum and both active and chronic gastritis in the gastric body of immunised $H$ pylori challenged mice but this still only represented a very mild degree of inflammation. Thus there was little evidence of post-immunisation gastritis in immunised mice challenged with $H$ pylori.

Analysis by ELISA revealed no correlation between the development of Helicobacter specific serum antibodies and the development of post-immunisation gastritis. Anti-Helicobacter antibodies in immunised mice challenged with $H$ felis - that is, those which exhibited postimmunisation gastritis - were no different from infected control mice (fig 2). In contrast, in immunised mice challenged with $H$ pylori where there was little if any increased gastritis, there was a dramatic increase in both serum IgG and IgA anti-H pylori antibodies (fig 2).

LONG TERM FOLLOW UP OF POST-IMMUNISATION GASTRITIS IN IMMUNISED MICE CHALLENGED WITH $H$ FELIS

Groups of C57BL/6 mice were left completely untreated (non-infected), treated with CT alone before infection with $H$ felis (infected), or immunised with $H$ felis lysate and CT before challenge with $H$ felis (immunised/challenged). Non-infected $(n=5)$, infected $(n=8)$, and immunised/challenged $(n=8)$ mice were sacrificed at three, six, 12, and 18 months post-challenge and bacterial colonisation and gastric pathology assessed as for the first experiment described above.

This experiment effectively followed the mice throughout their lifespan and so noninfected controls were used to allow for any effects of aging on stomach pathology. Even at the 18 month time point, in effect 20 months after the commencement of the experiment, the control mice exhibited no evidence of gastritis. We can thus be confident that the pathology seen in the other two groups was a result of $H$ felis infection with or without immunisation.

Immunisation with $H$ felis lysate and CT was effective at reducing bacterial colonisation (in all immunised mice) and maintained this reduction for at least 12 months post-challenge (table 3$)$. At the 18 month time point, the difference in colonisation between the immunised/challenged and infected mice was not significantly different.

Post-immunisation gastritis which was apparent at one month post-challenge in the first experiment was still evident at three months, with similar increases in neutrophil infiltration into the gastric body, atrophy, and with a higher neutrophil infiltration in the crypts and lumina (GAIS) in the immunised mice compared with those only infected. This increased inflammatory response however was transient, as at six months and all time points following this there was no significant difference in the two gastritis scores. The only exception was the reduction in lymphoid aggregates/follicles in immunised

Table 3 Assessment of post-immunisation gastritis and Helicobacter felis colonisation. Long term assessment of post-immunisation gastritis and H felis colonisation. Bacterial colonisation and gastric pathology were assessed in control, infected, or immunised/challenged mice, 3, 6, 12, and 18 months post-challenge with $H$ felis

\begin{tabular}{|c|c|c|c|c|c|c|c|c|c|c|}
\hline \multirow[b]{2}{*}{ Group } & \multirow{2}{*}{$\begin{array}{l}\text { Time point } \\
\text { (months) }\end{array}$} & \multicolumn{2}{|l|}{ Antrum } & \multicolumn{2}{|l|}{ Body } & \multirow{2}{*}{$\begin{array}{l}\text { Lymphoid } \\
\text { aggregates / } \\
\text { follicles }\end{array}$} & \multirow[b]{2}{*}{ GAIS } & \multirow[b]{2}{*}{ Atrophy } & \multirow{2}{*}{$\begin{array}{l}\text { Submucosal } \\
\text { inflammation }\end{array}$} & \multirow{2}{*}{$\begin{array}{l}\text { Colonisation } \\
\text { grade }\end{array}$} \\
\hline & & Neutrophils & $C I$ & Neutrophils & $C I$ & & & & & \\
\hline \multirow[t]{4}{*}{ Non-infected } & 3 & $1(0-1)$ & $1(1)$ & $0(0-1)$ & $1(0-1)$ & $0(0)$ & $0(0)$ & $0(0)$ & $0(0)$ & $0(0)$ \\
\hline & 6 & $0(0-1)$ & $0(0-1)$ & $0(0)$ & $0(0-1)$ & $0(0)$ & $0(0)$ & $0(0)$ & $0(0)$ & $0(0)$ \\
\hline & 12 & $0(0-1)$ & $0(0-1)$ & $0(0-1)$ & $0(0-1)$ & $0(0)$ & $0(0)$ & $0(0)$ & $0(0)$ & $0(0)$ \\
\hline & 18 & $0(0)$ & $0(0-1)$ & $0(0)$ & $0(0-1)$ & $0(0)$ & $0(0)$ & $0(0)$ & $0(0)$ & $0(0)$ \\
\hline \multirow[t]{4}{*}{ Infected } & 3 & $1(1-3)$ & $2(1-2)$ & $1.5(0-3)$ & $2(1-4)$ & $3.5(0-8)$ & $2(0-10)$ & $0(0-2)$ & $1(0-3)$ & $2.75(1.5-4)$ \\
\hline & 6 & $2(1-2)$ & $2(1-3)$ & $3(1-4)$ & $3(2-5)$ & $5(2-11)$ & $7(0-11)$ & $1(0-3)$ & $2.5(0-4)$ & $3(1.5-3.5)$ \\
\hline & 12 & $2(1-3)$ & $2.5(1-3)$ & $3(1-4)$ & $3(2-5)$ & $2.5(0-10)$ & $5(0-25)$ & $1(0-2)$ & $3(0-5)$ & $3.5(1.5-4)$ \\
\hline & 18 & $1(0-4)$ & $2(1-3)$ & $2(0-6)$ & $4(1-5)$ & $2(1-10)$ & $8(0-24)$ & $2(0-3)$ & $4(1-5)$ & $2.75(0.5-4)$ \\
\hline \multirow{5}{*}{$\begin{array}{l}\text { Immunised/ } \\
\text { challenged }\end{array}$} & & & & & & & & & & \\
\hline & 3 & $2(1-3)$ & $2(1-3)$ & $5(2-5)^{\star}$ & $3(2-4)$ & $0(0-2) \dagger$ & $12(0-21)^{\star}$ & $2.5(1-3)^{\star}$ & $3(1-4)$ & $1(0-2) \dagger$ \\
\hline & 6 & $2(1-3)$ & $2(1-2)$ & $3(1-4)$ & $3.5(1-5)$ & $1(0-5) \dagger$ & $8(0-12)$ & $2.5(0-3)$ & $3(0-4)$ & $0.75(0-3) \dagger$ \\
\hline & 12 & $2(0-3)$ & $2(0-3)$ & $1.5(0-5)$ & $3.5(0-6)$ & $0(0-2) \dagger$ & $1(0-3)$ & $2(0-3)$ & $3(0-4)$ & $0(0-1) \dagger$ \\
\hline & 18 & $1(0-3)$ & $2(1-3)$ & $2(1-3)$ & $4(1-5)$ & $0(0-5) \dagger$ & $2(0-16)$ & $2(0-3)$ & $3(0-5)$ & $1.5(0-4)$ \\
\hline
\end{tabular}

CI, chronic inflammation; GAIS, gland active inflammatory score.

All scores are median (range).

${ }^{\star}$ Significantly greater than the corresponding value in the infected control group ( $<<0.0125$; Mann-Whitney); †significantly lower than the corresponding value in the infected control group $(\mathrm{p}<0.0125$; Mann-Whitney). 
mice which was maintained for the length of the study.

Statistical analysis of changes in gastritis in infected mice over time revealed that there was no significant increase in gastritis from three to 18 months except for a progressive development of submucosal inflammation (KruskalWallis; $\mathrm{p}<0.015)$. In contrast, immunised/ challenged mice actually exhibited a significant decrease over time in both neutrophil infiltration into the body and in the number of GAIS (Kruskal-Wallis; p<0.02).

\section{Discussion}

A potential complication in developing a human vaccine against $H$ pylori is the observation in mice that prophylactic immunisation against Helicobacter infection with subsequent bacterial challenge can lead to an exacerbated pathological response. ${ }^{1314} 17$ The pathology associated with this post-immunisation gastritis can sometimes be severe and in the human would clearly be unacceptable as, if maintained, could potentially increase the chance of developing Helicobacter associated conditions such as peptic ulcer disease and gastric cancer. Here, we have described two experiments where this phenomenon was studied.

In the first short term study, postimmunisation gastritis was assessed following prophylactic immunisation of C57BL/6 mice and challenge with either $\mathrm{H}$ felis or $\mathrm{H}$ pylori. Challenge with $H$ felis induced a significant increase in pathology in immunised mice, including the development of what we have termed functional atrophy. ${ }^{18}$ In contrast, immunised mice challenged with $H$ pylori did not show gastric pathology, apart from a mild degree of chronic gastritis in the antrum and mild active body gastritis. This gastritis, particularly the antral lymphocyte population, most likely constitutes the effective immune response induced by immunisation, as the antrum is the major site of bacterial colonisation. It is known that CD4+ T lymphocytes are essential for effective immunity against $H$ pylori infection ${ }^{1920}$ and thus migration of these cells to the site of infection is to be expected.

It has been proposed that post-immunisation gastritis is driven by residual bacteria which the immune response fails to clear. ${ }^{13}$ Thus the presence of these bacteria maintain the inflammatory response, explaining why the immunised mice did not have lower gastritis scores than the infected controls. If these mice are cleared of infection by antimicrobial therapy then gastritis abates. ${ }^{13}$ Despite realising the need for bacterial antigen to drive the observed post-immunisation gastritis, the mechanisms involved are not understood. However, our data suggest that the humoral response does not play an important role due to the inverse relationship between serum anti-Helicobacter antibody levels and development of postimmunisation gastritis. Immunised mice challenged with $H$ felis which developed postimmunisation gastritis presented no change in their serum antibody response against Helicobacter antigen compared with infected controls. In contrast, immunised mice challenged with
$H$ pylori developed a large humoral response but without significant gastric pathology. Thus it appears that post-immunisation is a cell mediated phenomenon, although the effects of locally produced antibodies cannot be discounted.

It is worth noting that strain SS1 of H pylori is relatively avirulent in the mouse, as shown by the low gastritis scores in the infected mice. Thus it is possible that the absence of post-immunisation gastritis in these $H$ pylori challenged mice may be at least partly due to the poor virulence of these bacteria. Against this argument however is the study of Goto and colleagues. ${ }^{14}$ In contrast to our findings, Goto et $a l$, using basically the same model of C57BL/6 mice and $H$ pylori SS1, reported that postimmunisation gastritis is associated with protection against $H$ pylori challenge in mice. ${ }^{14}$ So why have two similar studies produced such different conclusions? We believe the explanation lies in the time at which the mice were challenged. Goto et al challenged mice one week after the final vaccination when the immunisation induced immune response was maximal. At this time, the immunised mouse would possess large numbers of highly activated Helicobacter specific lymphocytes. On challenge at this time, the activated lymphocytes would migrate rapidly into the site of infection and induce the observed strong inflammatory response. In our experiment, mice were not challenged until four weeks after the final immunisation when the immune response induced by immunisation would have significantly reduced. Thus there would have been far fewer activated Helicobacter specific lymphoid cells in our mice to induce the rapid gastritis observed in post-immunisation gastritis. It is important to note however that the vast majority of infections with $H$ pylori occur during childhood. For a prophylactic vaccine, it would clearly be necessary to immunise young children. Given the large numbers of individuals this would entail, a very low proportion of those immunised may well be infected shortly following vaccination and those individuals would possibly develop an accelerated inflammatory response. We propose that this phenomenon is part of the immune response induced by the vaccination to combat infection, and as suggested by this study, involves a transient increase in gastritis. Progression to the pathologies induced by $H$ pylori infection, such as peptic ulcers and gastric cancer, occur due to a chronic gastritis normally requiring many years. If a truly effective human vaccine is developed that produces sterilising immunity, there should be no significant health risk as the acute increase in gastritis should resolve to a complete absence of gastritis, provided the final vaccine is truely effective.

Despite the lack of pathology in the immunised mice challenged with $H$ pylori, the possibility of later development of postimmunisation gastritis cannot be ruled out by this study. However, we propose that this is unlikely as post-immunisation gastritis appears to be an acceleration of the normal long term inflammatory response observed following 
Helicobacter infection of non-immunised animals. This view is supported by our second experiment which followed the long term consequences of challenging immunised mice with $H$ felis. $H$ felis was used as it produces much greater gastritis in mice than does $H$ pylori and was thus considered the best model.

It is important to distinguish between gastritis and post-immunisation gastritis. Postimmunisation gastritis is exacerbation of gastritis induced by immunisation whereas gastritis is obviously the standard inflammatory response induced, in this case, by infection. In this study, post-immunisation gastritis was assessed between three and 18 months postchallenge. Post-immunisation gastritis was present at three months, as shown by active and chronic inflammation with atrophy in immunised/challenged mice (table 3). However, from six months onwards, by the same parameters this inflammatory response in the immunised and challenged group had significantly reduced compared with the infected group. This supports the view that postimmunisation gastritis - that is, exacerbation of gastritis induced by immunisation - is a transitory phenomenon which disappears over time. It is important to note that these mice still develop gastritis to the same level as control mice.

Immunisation produced a long term reduction in bacterial burden which lasted for at least a year, half the life of the mouse. There was apparently no significant effect after 18 months, but this may, at least partly, be due to the increased atrophy in the control infected mice reducing the colonisation score in these mice. The increased pathology makes the histological grading of colonisation more difficult, and could also possibly exert an environmental impact on the Helicobacter. However, it also needs to be noted that there was a slight increase in colonisation of the immunised mice. This suggests that a booster vaccination could be required for very long term protection, although the data required to conclude this are not currently available. Such boosters are a common feature of many currently available vaccines such as those against polio, tetanus, and hepatitis $\mathrm{B}$. In the context of a $H$ pylori vaccine, this may not be important given that most infections occur during childhood.

Also of note from this study is the fact that immunisation significantly reduced the formation of lymphoid aggregates/follicles in the gastric mucosa. This observation suggests that immunity may be redirected away from the formation of the MALT response. Infection with $H$ pylori can lead to the development of $\mathrm{B}$ cell MALT lymphomas. ${ }^{1-3}$ These Helicobacter induced MALT lymphomas typically develop in the marginal zone of lymphoid follicles which are present in gastric tissue as a result of chronic infection. ${ }^{21}$ Thus the absence of a lymphoid follicular response may prevent development of MALT lymphomas.

In summary, we have presented evidence which suggests that prophylactic immunisation against $H$ pylori infection can induce an effective immune response without the development of significant pathology. Most importantly, we have also shown that when an immunisation induced exacerbation of pathology did occur, the effects were transient and additionally prevented the formation of lymphoid follicles. Safety issues are paramount in the development of any human vaccine, and for $H$ pylori this is no exception. The observation of post-immunisation gastritis seen in some animal models needs to be addressed. The $H$ felis mouse model of post-immunisation gastritis is the most extreme example of this type of pathology. We have shown in this model that post-immunisation gastritis is a transient event with no long term exacerbation of pathology. This should provide reassurance regarding the safety of a final human vaccine against $H$ pylori infection in humans. However, it is important to note that even though vaccination did not induce any long term increase in gastritis, neither did it produce any reduction in gastric inflammation, despite a significant reduction in bacterial burden. This is due to the unfortunate inability of current vaccination regimens to induce complete protection against Helicobacter infection. Antigens produced by the residual bacteria are still sufficient to drive an equivalent inflammatory response. The solution is to improve the vaccine so that sterilising immunity can be achieved and when this occurs, the gastritis should disappear once and for all.

This work was funded by CSL Limited, Melbourne and the National Health and Medical Research Council, Australia.

1 Yamada T, Ahnen D, Alpers DH, et al. Helicobacter pylori in peptic ulcer disease. $\mathcal{F A M A}$ 1994;272:65-9.

2 IARC. IARC Monographs on the evaluation of carcinogenic risks to humans. Lyon: World Health Organisation, 1994:177-240.

3 Isaacson PG. Mucosa-associated lymphoid tissue lymphoma. Semin Hematol 1999;36:139-47.

4 Megraud F. Antibiotic resistance in Helicobacter pylori infection. Br Med Bull 1998;54:207-16.

5 Chen M, Lee A, Hazell SL. Immunisation against Helicobacter infection in a mouse/Helicobacter felis model. Lancet 1992;339:1120-1.

6 Czinn SJ, Cai A, Nedrud JG. Protection of germ-free mice from infection by Helicobacter felis after active oral or passive IgA immunization. Vaccine 1993;11:637-42.

7 Chen MH, Lee A, Hazell S, et al. Immunisation against gastric infection with Helicobacter species-first step in the prophylaxis of gastric cancer? Zbl Bakt (Int $\mathcal{f}$ Med Microbiol) 1993;280:155-65.

8 Michetti P, Corthesy-Theulaz I, Davin C, et al. Immunisation of $\mathrm{BALB} / \mathrm{c}$ mice against Helicobacter felis infection with H. pylori urease. Gastroenterology 1994;107:1002-11.

9 Radcliff FJ, Hazell SL, Kolesnikow T, et al. Catalase, a novel antigen for Helicobacter pylori vaccination. Infect Immun 1997;65:4668-74.

10 Ghiara P, Rossi M, Marchetti M, et al. Therapeutic intragastric vaccination against Helicobacter pylori in mice eradicates an otherwise chronic infection and confers protection against reinfection. Infect Immun 1997;65:49965002 .

11 Doidge C, Gust I, Lee A, et al. Therapeutic immunisation against Helicobacter infection. Lancet 1994;343:914-15.

12 Corthesy Theulaz I, Porta N, Glauser M, et al. Oral immunization with Helicobacter pylori urease B subunit as a treatment against Helicobacter infection in mice. Gastroenterology 1995;109:115-21.

13 Ermak TH, Ding R, Ekstein B, et al. Gastritis in urease-immunized mice after Helicobacter felis challenge may be due to residual bacteria. Gastroenterology 1997;113: $1118-28$

14 Goto T, Nishizono A, Fujioka T, et al. Local secretory immunoglobulin A and postimmunization gastritis correlate with protection against Helicobacter pylori infection after oral vaccination of mice. Infect Immun 1999;67:25319.

15 Lee A, Fox JG, Otto G, et al. A small animal model of human Helicobacter pylori active chronic gastritis. Gastroenterology 1990;99:1315-23. 
16 Lee A, O'Rourke J, De Ungria MC, et al. A standardized mouse model of Helicobacter pylori infection-introducing

17 Dieterich C, Bouzourene H, Blum AL, et al. Urease-based mucosal immunization against Helicobacter heilmanni infection induces corpus atrophy in mice. Infect Immun 1999;67:6206-9

18 Sutton P, Wilson J, Genta R, et al. A genetic basis for atrophy: dominant non-responsiveness and helicobacter induced gastritis in F-1 hybrid mice. Gut 1999;45: 335-40.
19 Ermak TH, Giannasca PJ, Nichols R, et al. Immunization of mice with urease vaccine affords protection against Helicobacter pylori infection in the absence of antibodies and is mediated by MHC class II-restricted responses. 7 Exp Med

20 Pappo J, Torrey D, Castriotta L, et al. Helicobacter pylori infection in immunized mice lacking major histocompatibility complex class I and class II functions. Infect Immun 1999;67:337-341.

21 Isaacson PG. Gastric MALT lymphoma: From concept to cure. Ann Oncol 1999;10:637-45.

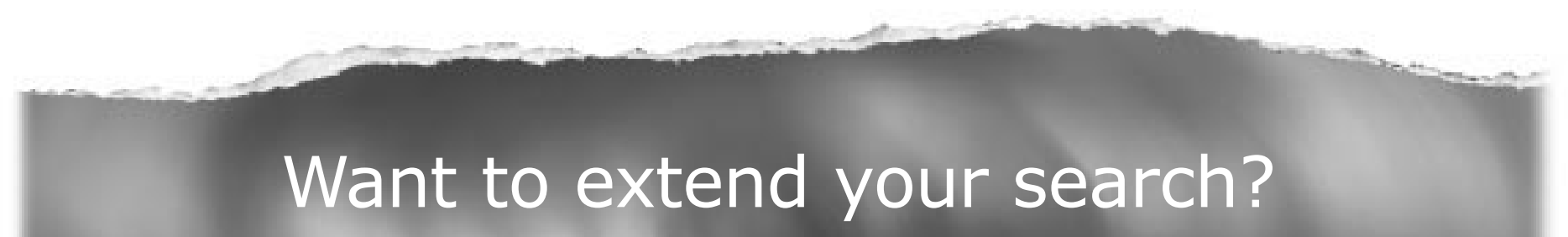

Cross journal searching

If you can't find what you are looking for in Gut you can extend your search across many of the more than 200 journals available for selection. You can restrict your search to specific subject areas

(eg, clinical medicine, basic research), or select specific journals, or search all available titles.

\section{www.gutjnl.com}

